\title{
К ВОПРОСУ ОБ ОСОБЕННОСТЯХ ИНФОРМАЦИОННОГО ПРОТИВОСТОЯНИЯ РОССИИ И гРУЗИИ
}

Аннотация: Предметом является деятельность средств массовой информации в ходе военных и политических конфликтов в частности, их роль и место в ходе информационного противостояния, которым сопровождался Южно-Кавказский конфликт 2008 года. В статье рассматриваются истоки, особенности, характер и основные вехи информационного противостояния России и Грузии в 1991-2014 годах. Предлагается периодизация данного противостояния, выделяются его особенности, проявившиеся в ходе информационной войны 2008 года, оценивается их современное состояние. Теоретическими основами работы выступят труды отечественных и зарубежных ученых - специалистов в области конфликтологии, современных информационных и политических процессов. При работе использованы системный, диалектический, логический, и функииональный методы, методы анализа и синтеза, эмпирические методы, метод прогнозных сиенариев, контент-анализа Научная новизна исследования будет заключаться 6 обосновании новых подходов к роли и месту средств массовой информации в ходе военных и политических конфликтов, уточнении механизмов информационного противостояния в современных условиях, а также в использовании концептуальных наработок при изучении информационного противостояния в контексте российско-грузинских отношений. Значимыли, также, являются систематизация и обобщение мнений сложившихся относительно событий августа 2008 года, в международной и национальной прессе. Материаль исследования, тем самым, смогут использоваться при дальнейшем изучении выявленной проблематики, а также смежных, по отношению к ней, тематик.

Abstract: The subject of this research is the work of mass media and its role in the informational confrontation during the Russo-Georgian conflict of 2008. The article reviews the origins, specifics, character and the main milestones of the informational warfare between Russia and Georgia during the period of 1991-2014. The author offers the periodization of this conflict, highlights its details that emerged during the informational war of 2008, and offers an assessment of its current status. The theoretical fundament of this work is the research of Russian and foreign scholars, experts in conflict resolution and modern informational and political processes. The methodology behind this work includes: systemic, dialectic, logical, functional, analysis and synthesis, empirical, prognostic scenario analysis, and content analysis. The scientific novelty of this research consists in the substantiation of the new approaches to the role of mass media during military and political conflicts, identification of the mechanisms of informational warfare in the modern world, as well as use of conceptual progress in the context of Russia-Georgia relations.

Ключевые слова: Грузия, Россия, медиа, информачионное противостояние, южная осетия, война, взаимоотночения, политика, конфликт, средства массовых коммуникаций.

Keywords: Georgia, Russia, media, information warfare, South Ossetia, war, relations, politics, conflict, mass communication.

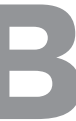

заимоотношения Российской Федерации и Грузии, начиная с 1991 года, весьма сложны и неоднозначны. Не вдаваясь, подробно, в политическую историю этих взаимоотношений (тем более что ее трактовки, как со стороны России, так и Грузии, противоречивы), тем не менее, отметим, что она, по сути, представляет собой скорее историю противостояния (тайного или явного), чем историю взаимовыгодного сотрудничества государств-соседей.

Причин этому, можно выделить весьма много это и особенности понимания сторонами абхазского, югоосетинского и чеченского вопросов, и проблема Панкисского ущелья, и особенности внешней политики обоих государств и целый комплекс других проблем и противоречий 1 .

Наивысшей точкой межгосударственных противоречий Грузии и России, необходимо считать известные события августа 2008 года, после которых, дипломатические отношения между странами были прекращены. Отметим и то, что, несмотря на некоторые позитивные тенденции последних лет, говорить о преодолении взаимовыгодных разногласий и о

\footnotetext{
${ }^{1}$ См. подр.: Илларионов В.П., Микеладзе О.А. Россия и Грузия: размышления о прошлом, настоящем, будущем. - М.: ОлмаПресc, 2005.
} 
переходе к взаимовыгодному сотрудничеству, явно преждевременно.

Отличительной особенностью этих взаимоотношений - фактически начиная с 1991 года и по современный период, является информационное противостояние, основным проводником которого, являются СМИ (в дальнейшем СМК) обеих стран.

При этом, начиная со второй половины 2008 года (пик противоборства) действующими акторами этого информационного противостояния, становятся также западные (в основном европейские и американские) Средства массовой коммуникации. В настоящее время «накал» этого противостояния несколько спал, однако оно явно не завершено.

Если рассматривать в качестве предмета исследования именно информационное противостояние двух стран, то историю этого противостояния, можно разделить (достаточно условно) на три этапа:

- 1 этап - этап, в ходе которого проявились истоки информационного противостояния России и Грузии, включает в себя 1991 - 2005 годы. Он включает в себя период объявления независимости Грузии, начало двусторонних контактов между независимыми Грузией и Россией, период президентства 3. Гамсахурдия, Э. Шеварднадзе, Революцию Роз, короткий период временного президентства Н. Бурджанадзе, а также начало правления М. Саакашвили. В этот период, говорить о каком-либо организованном информационном противостоянии преждевременно, однако очевидно, что трактовка отдельных позиций, в информационном поле двух стран, была различной. Однако это имело ограниченный характер, а векторы были неоднозначны и часто менялись.

До 2003 года, считалось, что до М. Саакашвили натянутые отношения между Грузией и Россией можно было объяснить «фактором Шеварднадзе»².

Однако с приходом к власти Саакашвили они значительно ухудшились, хотя на протяжении первого года правления М. Саакашвили (до 2005 года), была надежда обеих сторон, что с приходом к власти нового руководства Грузии, российско-грузинские отношения изменятся к лучшему ${ }^{3}$.

К сожалению, этого не произошло, вследствие активного сближения Грузии с западными странами и откровенной антироссийской риторикой новых лидеров

\footnotetext{
2 Стрельцов В. Грузия, которую мы потеряли // Независимая газета. - 2002. - 20 февраля; Суслов Д. Мир дистанцировался от Шеварднадзе // Независимая газета. - 2003. - 24 ноября.

${ }^{3}$ Саакашвили М. Отношения Грузии и России оттаяли. // Независимая газета. - 2005. - 11 декабря.
}

Грузии, которая спровоцировала ответные действия со стороны российского информационного поля ${ }^{4}$.

К 2005 году, информационные «уколы» с обеих сторон, принимают перманентный характер. Широкое развитие информационных технологий, проходившее в этот период, привело к тому, что информационное противоборство обеих сторон, в этот период, «перерастает» уровень СМИ и начинает активно использовать медиа-ресурсы - в первую очередь Интернет. С этого периода можно говорить о новом этапе в информационном противостоянии России и Грузии.

Упомянутый 2 этап - 2005-2012 годы, уже можно оценить как информационное противостояние, переходящее в информационную войну. Верхний предел этого периода, ознаменован переходом к публичному выражению имеющихся противоречий со стороны официальных лиц (что самым непосредственным образом отразилось и на информационном поле России и Грузии), а также очевидным разворотом во внешней политике Грузии. Во второй половине 2008 года (после пятидневной войны) противостояние обретает характер информационной войны (к участию в которой были привлечены и СМК западных стран), причем, войны совершенного нового типа 5 .

Поворотным пунктом для ухудшения двусторонних отношений в информационном поле, можно считать известные события 2006 года, когда Грузия ввела воинские подразделения в Кодорское ущелье. Затем имело место демонстративное выдворение из Грузии в конце 2006 года арестованных четырёх российских военных (офицеров ГРУ), объявленных шпионами, что не могло не вызвать негативной реакции в России; и существует обоснованное мнение, что это было сделано именно в расчёте на то, чтобы вызвать подобную реакцию.

По сути, к августу 2008 года Москва и Тбилиси имели в активе:

1) совершенную разновекторность внешней политики;

2) грандиозные взаимные обвинения в организации терактов и потворстве терроризму;

3) шпионские скандалы;

4) нерегулярное прямое транспортное сообщение;

5) одностороннее торговое эмбарго;

6) массовую депортацию граждан Грузии из России;

\footnotetext{
${ }^{4}$ Мурванидзе Б.Ю. Россия и США в ориентирах внешней политики Грузии в период президентства Эдуарда Шеварднадзе: автореф. дисс. канд. истор. наук. - Иваново, 2009. - С. 21.

${ }^{5}$ Новиков В. К. Информационное оружие - оружие современных и будущих войн. - 2-е изд., испр. - М.: Горячая линия - Телеком, 2013.
} 
DOI: 10.7256/1811-9018.2014.11.13266

При цитировании этой статьи сноска на dоі обязательна

\section{Право и политика $11(179) \cdot 2014$}

7) отозванного из Москвы грузинского посла

8) жесткий визовый режим;

9) крайне болезненное для Тбилиси распоряжение Владимира Путина об особенных экономических отношениях России с Абхазией и Южной Осетией.

Информационным следствием военного конфликта 2008 года, стало то, что он стал одной из самых обсуждаемых тем в российских и в западных СМК. На интернет-сайтах и в информационных агентствах появилось тысячи упоминаний данного конфликта.

Российская, грузинская и западная пресса, кардинально расходясь в оценке произошедших событий, соглашались лишь в одном - ни Осетия с Абхазией, ни Грузия с Россией уже не вернутся к прежним отношениям.

Явной особенностью данного противостояния, необходимо признать тот факт, что в его ходе широкую популярность получила новая информационная модель, благодаря которой влияние государственных акторов стало весомым. Эту модель можно условно назвать моделью «провластного агента» ${ }^{6}$.

Данная модель заключается в том, что информационная война ведется не по официальным каналам (таким как официальные сайты ведомств или даже сайты СМИ), а через «инсайдеров»- блоги, сайты, и т.д. Другими особенностями, было широкое блокирование сегментов интернета и создание сторонами, по сути альтернативных моделей медиа-реальности.

Оценивая информационные итоги противостояния России и Грузии, к 2012 году - периоду изменений во внутренний и внешней политике Грузии, переход к которым ознаменовал начало нового этапа в информационном противостоянии, отметим, что они неоднозначны. Однако на наш взгляд, вопрос о выигрыше или проигрыше в этой войне, объективно не так важен.

Важен сам факт создания как минимум двух моделей медиа-реальности (Грузия-Запад и Россия с рядом союзников) в которых оценки происходящего имели совершенно разную направленность, при сохранении действующего статус-кво (Абхазия и Южная Осетия дефакто не являются частью Грузии) не могло представлять собой базу, для какого либо решения конфликта. Это было понятно и в Грузии и в России, и на Западе;

Состояние этой, необъявленной войны, по сути, сохранялось вплоть до 2012 года (накал ее, однако, с 2008 года, несколько снизился) - до внутриполитических изменений в Грузии, в ходе которых «Единое национальное движение» - партия М. Саакашвили

${ }^{6}$ Панфилов О. Россия-Грузия: информационная война. Август 2008 года. М.: Центрполиграф, 2011. - С.68 проиграла на выборах, а сам Президент, начинает стремительно терять популярность и фактическое влияние в стране. С этого момента, начинается новый, современный этап информационного противостояния.

Данный этап (с 2012 года) можно кратко охарактеризовать как отход от состояния «информационной войны» к предыдущему состоянию - информационному противостоянию, которое, однако, по сути, идет на спад. К 2012 году, обоюдно направленная риторика, фактически потеряла свою остроту, чему, в частности, способствовал и происходивший в Грузии политический процесс, в ходе которого к власти в стране пришли новые политики, воздерживающиеся от антироссийской риторики. Это привело к появлению новых тенденций в информационном противостоянии.

Как в российском, так и грузинском информационных полях, результаты парламентских выборов 2012 года, были восприняты как хороший шанс для улучшения российско-грузинских отношений 7 .

Однако современный курс на развитие политических отношений проводится, разумеется, с целью расширения экономического партнерства между двумя странами, а не с целью достижения, какого либо политического урегулирования, которое пока не возможно.

В частности, необходимо отметить, что нынешнее грузинское правительство убеждено, что возобновление дипломатических отношений между Грузией и Россией возможно только в случае прекращения оккупации российскими войсками Абхазии и Южной Осетии и отмены заявления Москвы о признании независимости этих республик. Однако Кремль много раз отвергал это предложение, заявляя, что данная тема даже не обсуждается ${ }^{8}$.

Одним из важнейших параметров в отношениях двух государств является проблема ориентации Грузии на Запад, которая в период президентства Саакашвили постоянно подвергалась критике со стороны России. С уходом этого президента и формированием в Тбилиси нового правительства стали строиться предположения о том, что Грузия, по крайней мере, уменьшит темпы своего сближения с Западом, однако пока никаких признаков этого все еще не наблюдается9.

\footnotetext{
${ }^{7}$ См. напр.: Гегешидзе А. Изменения во внешней политике Грузии? // Свободная Грузия. - 27 декабря 2012 года

${ }_{8}^{8}$ Андрианов Н.С. Грузино-юго-осетинский конфликт: специфика политического урегулирования: дисс. ... канд. полит. наук. - Нижний Новгород, 2012. - С. 11.

${ }^{9}$ Новые перспективы российско-грузинских отношений // Электронный ресурс. Режим доступа. http://www.otechestvo.org. ua/main/201312/2731.html
} 
В то же время, нельзя не отметить, что Грузия, которая, исходя из своего нынешнего положения, больше заинтересована в налаживании диалога с Москвой, сделала первые шаги и гораздо больше примирительных жестов, чем Россия.

Оценивая информационную составляющую современных российско-грузинских отношений, можно сделать вывод о том, что в информационных полях двух стран, все чаще звучат мнения о необходимости нормализации отношений, возможности которой, однако, в силу неразрешимости вопросов об Абхазии и Южной Осетии, пока весьма ограниченные. Отметим и то, что информационное поле Грузии (и, как следствие, общественное мнение этой страны) более активно в поиске возможных в данной ситуации вариантов.

Информационное противостояние, на данном этапе, по сути, продолжается, однако высказываемые мнения, с обеих сторон, уже не столь категоричны и гораздо чаще настроены на поиск компромиссов. Сам факт снижения накала информационного противосто- яния в отношениях между странами, можно в качестве одного из немногих фактов, свидетельствующих о том, что компромисс, все-таки возможен даже в сложившейся ситуации.

Завершая настоящую статью, отметим, что, несмотря на все негативные следствия информационного противостояния России, и Грузии уроки их, безусловно, следует учитывать при формировании современных векторов политики Российской Федерации.

Информация, в настоящее время, это сильнейшее оружие войны. Как показали недавние события, связанные с крымским кризисом, уроки информационного противостояния, Россией, в полной мере учтены не были, хотя, конечно, ее действия в информационном поле имели более смелый и решительный характер. Голосование в ООН 27 марта 2014 года, показало, что мнения мирового сообщества, по сути, были разделены на две части - результат, который, безусловно, перекрывает масштабы международной поддержки России в 2008 году.

\section{Библиография:}

1. Андрианов Н.С. Грузино-юго-осетинский конфликт: специфика политического урегулирования: дисс. ... канд. полит. наук. - Нижний Новгород, 2012. - 28 с.

2. Гегешидзе А. Изменения во внешней политике Грузии? // Свободная Грузия. - 27 декабря 2012 года. - С. 2-4.

3. Илларионов В.П., Микеладзе О.А. Россия и Грузия: размышления о прошлом, настоящем, будущем. - М.: Олма-Пресс, 2005. -230 c.

4. Мурванидзе Б.Ю. Россия и США в ориентирах внешней политики Грузии в период президентства Эдуарда Шеварднадзе: автореф. дисс. канд. истор. наук. - Иваново, 2009. - 29 с.

5. Новиков В.К. Информационное оружие-оружие современных и будущих войн. - 2-е изд., испр. - М.: Горячая линияТелеком, 2013. - 264 с.

6. Новые перспективы российско-грузинских отношений // Электронный ресурс. Режим доступа. http://www.otechestvo. org.ua/main/201312/2731.html

7. Панфилов О. Россия-Грузия: информационная война. Август 2008 года. М.: Центрполиграф, 2011. - 248 с.

8. Саакашвили М. Отношения Грузии и России оттаяли // Независимая газета. - 2005. - 11 декабря. - С. 2-3.

9. Стрельцов В. Грузия, которую мы потеряли // Независимая газета. - 2002. - 20 февраля. - С. 6-7.

10. Суслов Д. Мир дистанцировался от Шеварднадзе // Независимая газета. - 2003. - 24 ноября. - С. 3-5.

11. Бочарников И.В.. Новый курс грузинской внешней политики: сценарий «перезагрузки» // Международные отношения. - 2014. - № 2. - C. 104-107. DOI: 10.7256/2305-560Х.2014.2.11366

12. Алейников А.В. Системные конфликты в России: концептуальные основания анализа. Статья 1. // NB: Проблемы общества и политики. - 2013. - 7. - C. 94 - 140. DOI: 10.7256/2306-0158.2013.7.2306. URL: http://www.e-notabene.ru/ pr/article_2306.html

13. Алейников А.В. Системные конфликты в России: концептуальные основания анализа. Статья II. // NB: Проблемы общества и политики. - 2013. - 8. - C. 1 - 47. DOI: 10.7256/2306-0158.2013.8.5109. URL: http://www.e-notabene.ru/pr/article_5109.html

14. Бородинов Е.Н. Территориальный раскол и конфликт элит в Украине // Тренды и управление. - 2014. - 1. - C. 51 - 62. DOI: $10.7256 / 2307-9118.2014 .1 .11739$.

15. Журавель В.П. Борьба с терроризмом в современной России: итоги 2012 г. // Международные отношения. - $2013 .-2$. - C. 166 - 176. DOI: 10.7256/2305-560X.2013.02.9.

16. Виноградова Е.А. Информационная война: концептуальный анализ // Тренды и управление. - 2014. - 3. - С. 283 - 292. DOI: $10.7256 / 2307-9118.2014 .3 .12722$.

17. Курилкин А.В. Теоретико-методологические основы исследования информационных войн и психологических операций // Тренды и управление. - 2014. - 3. - С. 264 - 270. DOI: 10.7256/2307-9118.2014.3.12748.

18. Петренко А.И. Теоретические основы организации противодействия использованию арсенала сил, средств и методов информационно-психологической войны в политических целях // Тренды и управление. - 2014. - 2. - C. 154 - 167. DOI: 10.7256/2307-9118.2014.2.12412. 
DOI: 10.7256/1811-9018.2014.11.13266

При цитировании этой статьи сноска на доі обязательна

\section{Право и политика $11(179) \cdot 2014$}

\section{References (transliterated):}

1. Andrianov N.S. Gruzino-yugo-osetinskii konflikt: spetsifika politicheskogo uregulirovaniya: diss. ... kand. polit. nauk. - Nizhnii Novgorod, 2012. $-28 \mathrm{~s}$.

2. Gegeshidze A. Izmeneniya vo vneshnei politike Gruzii? // Svobodnaya Gruziya. - 27 dekabrya 2012 goda. - S. 2-4.

3. Illarionov V.P., Mikeladze O.A. Rossiya i Gruziya: razmyshleniya o proshlom, nastoyashchem, budushchem. - M.: Olma-Press, 2005. - $230 \mathrm{~s}$.

4. Murvanidze B.Yu. Rossiya i SShA v orientirakh vneshnei politiki Gruzii v period prezidentstva Eduarda Shevardnadze: avtoref. diss. kand. istor. nauk. - Ivanovo, 2009. - 29 s.

5. Novikov V.K. Informatsionnoe oruzhie-oruzhie sovremennykh i budushchikh voin. - 2-e izd., ispr. - M.: Goryachaya liniyaTelekom, 2013. - $264 \mathrm{~s}$.

6. Panfilov O. Rossiya-Gruziya: informatsionnaya voina. Avgust 2008 goda. M.: Tsentrpoligraf, 2011. - $248 \mathrm{~s}$.

7. 8. Saakashvili M. Otnosheniya Gruzii i Rossii ottayali // Nezavisimaya gazeta. - 2005. - 11 dekabrya. - S. 2-3.

8. Strel'tsov V. Gruziya, kotoruyu my poteryali // Nezavisimaya gazeta. - 2002. - 20 fevralya. - S. 6-7.

9. Suslov D. Mir distantsirovalsya ot Shevardnadze // Nezavisimaya gazeta. - 2003. - 24 noyabrya. - S. 3-5.

10. Bocharnikov I.V.. Novyi kurs gruzinskoi vneshnei politiki: stsenarii «perezagruzki» // Mezhdunarodnye otnosheniya. - 2014. - № 2. - S. 104-107. DOI: 10.7256/2305-560X.2014.2.11366

11. Aleinikov A.V. Sistemnye konflikty v Rossii: kontseptual'nye osnovaniya analiza. Stat'ya 1. // NB: Problemy obshchestva i politiki. - 2013. - 7. - C. 94 - 140. DOI: 10.7256/2306-0158.2013.7.2306. URL: http://www.e-notabene.ru/pr/article_2306.html

12. Aleinikov A.V. Sistemnye konflikty v Rossii: kontseptual'nye osnovaniya analiza. Stat'ya II. // NB: Problemy obshchestva i politiki. - 2013. - 8. - C. 1 - 47. DOI: 10.7256/2306-0158.2013.8.5109. URL: http://www.e-notabene.ru/pr/article_5109.html

13. Borodinov E.N. Territorial'nyi raskol i konflikt elit v Ukraine // Trendy i upravlenie. - 2014. - 1. - C. 51 - 62. DOI: 10.7256/23079118.2014.1.11739.

14. Zhuravel' V.P. Bor'ba s terrorizmom v sovremennoi Rossii: itogi 2012 g. // Mezhdunarodnye otnosheniya. - 2013. - 2. - C. 166 - 176. DOI: 10.7256/2305-560X.2013.02.9.

15. Vinogradova E.A. Informatsionnaya voina: kontseptual'nyi analiz // Trendy i upravlenie. - 2014. - 3. - C. 283 - 292. DOI: 10.7256/2307-9118.2014.3.12722.

16. Kurilkin A.V. Teoretiko-metodologicheskie osnovy issledovaniya informatsionnykh voin i psikhologicheskikh operatsii // Trendy i upravlenie. - 2014. - 3. - C. 264 - 270. DOI: 10.7256/2307-9118.2014.3.12748.

17. Petrenko A.I. Teoreticheskie osnovy organizatsii protivodeistviya ispol'zovaniyu arsenala sil, sredstv i metodov informatsionno-psikhologicheskoi voiny v politicheskikh tselyakh // Trendy i upravlenie. - 2014. - 2. - C. 154 - 167. DOI: 10.7256/23079118.2014.2.12412. 